\title{
Microtensile Bond Strength, Marginal Leakage, and Antibacterial Effect of Bulk Fill Resin Composite with Alkaline Fillers versus Incremental Nanohybrid Composite Resin
}

\author{
Nada Ismail Mohamed ${ }^{1}$ Rehab Khalil Safy ${ }^{1} \quad$ Ahmed Fawzy Abo Elezz ${ }^{1}$ \\ ${ }^{1}$ Restorative Dentistry Department, Faculty of Dentistry, Suez Canal \\ University, Ismalia, Egypt \\ Address for correspondence Nada Ismail Mohamed, Department \\ of Restorative Dentistry, Faculty of Dentistry, Suez Canal University, \\ Eur J Dent 2021;15:425-432 \\ Ismailia 0064, Egypt (e-mail: nodg2010@yahoo.com).
}

\begin{abstract}
Keywords

- alkasite

- microtensile bond strength

- microleakage

- antibacterial effect

Objective This study aimed to investigate the microtensile bond strength ( $\mu \mathrm{TBS}$ ), microleakage, and antibacterial effect of bulk fill resin composite with alkaline fillers (alkasite) (alkaline fillers such as barium aluminum silicate glass and ytterbium trifluoride) in comparison to incremental nanohybrid resin composite.

Materials and Methods $\mu$ TBS was evaluated by using 30 human mandibular molars. Teeth were randomly divided into three groups (C): nanohybrid resin composite (CO), self-cured alkasite (C1), and dual-cured alkasite (C2). Each group was subdivided into two subgroups according to the bulk thickness: $4 \mathrm{~mm}$ (T1) and $6 \mathrm{~mm}$ (T2). The occlusal enamel of teeth was removed and the resin composite was applied to a flat dentin surface. Then, teeth were sectioned into beams to be tested under tension. For microleakage testing, mesio-occlusal class II cavities were prepared in 15 molars and divided into three groups as mentioned before. Following this, cavities were restored, thermocycled, immersed in a dye, sectioned mesiodistally, and then dye penetration was assessed. The antibacterial effect of both tested materials was evaluated using agar disc diffusion and broth dilution methods against chlorhexidine as a control positive group. Results There was no significant difference in $\mu$ TBS between all tested groups. Bulk fill self-cured alkasite showed the lowest microleakage value followed by bulk fill dual-cured alkasite and incremental nanohybrid resin composite, respectively. Also, cervical microleakage showed significantly higher mean value than the occlusal one. The antibacterial effect of alkasite was less than chlorhexidine. Alkasite showed maximum broth clarity at lowest tested bacterial concentration.

Conclusion Resin composite with alkaline fillers was characterized by good $\mu \mathrm{TBS}$ and marginal integrity with weak antibacterial effect.
\end{abstract}

\section{Introduction}

Contemporary resin composite materials are typically based on dimethacrylate resins that harden by free radical polymerization. ${ }^{1}$ Visible light activation is the primary way to trigger the polymerization reaction. ${ }^{2}$ Basically, polymerization occurs by adding dimethacrylate monomer molecules resulting in rapid growth and cross-linking

published online January 7, 2021
DOI https://doi.org/ 10.1055/s-0040-1721310 ISSN 1305-7456. of polymer chains. ${ }^{3}$ Unfortunately, the emitted light energy dramatically decreases when transmitted via resin composite material resulting in a gradual decrease in its degree of polymerization especially at an increasing distance from the irradiated surface. ${ }^{4}$ This decrease in the degree of polymerization jeopardizes physical properties and increases the elution of residual monomer from

(C) 2020. European Journal of Dentistry.

This is an open access article published by Thieme under the terms of the Creative Commons Attribution-NonDerivative-NonCommercial-License, permitting copying and reproduction so long as the original work is given appropriate credit. Contents may not be used for commercial purposes, or adapted, remixed, transformed or built upon. (https://creativecommons.org/licenses/by-nc-nd/4.0/)

Thieme Medical and Scientific Publishers Pvt. Ltd., A-12, 2nd Floor, Sector 2, Noida-201301 UP, India 
the resin composite material. Also, it may result in premature failure of a restoration that may affect the pulp tissue adversely. ${ }^{5}$ Therefore, to overcome all these drawbacks, incremental application of resin composite material was used as a gold standard method for resin composite application. ${ }^{6}$ In general, the maximum increment thickness was determined as $2 \mathrm{~mm} .{ }^{7}$ However, it was found to be time and effort consuming and may imply a risk of air bubble incorporation or contamination between the increments. Therefore, manufacturers introduced types of resin composites material "bulk fill" which are believed to be curable to a maximum increment thickness of $4 \mathrm{~mm} .{ }^{8}$

One of the drawbacks of the available bulk fill resin composite is having maximum curing depth not more than $4 \mathrm{~mm}$. ${ }^{9}$ Beyond fast processing and adequate curing in large increments, bulk fill resin composite requires additional features, such as bioactivity. ${ }^{10}$ So, a self-/dual-cured resin composite material with alkaline fillers categorized as "alkasite" was introduced to the market as bulk fill material. It was claimed that this material contains alkaline glass fillers capable of releasing substantial levels of fluoride. Besides this bioactivity, the manufacturer claimed that the material was characterized by an increased degree of polymerization in increment thickness more than $4 \mathrm{~mm}$, due to its availability in both self-/dual-cured modes. ${ }^{11} \mathrm{As}$ a trial to investigate these manufacturer's claims, the aim of the current study was directed at evaluation of microtensile bond strength ( $\mu \mathrm{TBS}$ ), marginal integrity, and antibacterial effect of this bulk fill resin composite material with alkaline fillers.

\section{Materials and Methods}

Materials' description, composition, manufacturers, and batch numbers are presented in $\boldsymbol{- T a b l e} \mathbf{1}$.

\section{Microtensile Bond Strength Test}

Thirty human impacted mandibular third molars freshly extracted for orthodontic distalization from patients in the age range 20 to 30 years were collected and used for preparation of $\mu$ TBS testing samples. Then, teeth were thoroughly washed under running water to remove blood and mucous, scaled to remove calculus and remnants of periodontal ligaments, and polished with fine pumice and soft rubber cups at conventional speed. Teeth were used with approval from the Research Ethics Committee of Faculty of Dentistry, Suez Canal University, Egypt (number 16/20170. Removal of the occlusal enamel and exposing of deep dentine was performed after fixing of each tooth in an acrylic resin block using automated diamond saw (Isomet 4000, Buehler Ltd., Lake Bluff, United States). Exposed dentin surfaces were further polished for removal of any debris with 600-grit silicon carbide sandpaper for 60 seconds. Then, samples were divided into three groups according to used resin composite material $(n=10)$, where $\mathrm{C} 0$, nanohybrid resin composite; $\mathrm{C} 1$, self-cured Cention $\mathrm{N}$; and $\mathrm{C} 2$, dual-cured Cention N. Each group was further subdivided into two subgroups according to the thickness of the resin composite material, where $\mathrm{T} 1,4 \mathrm{~mm}$ and T2, $6 \mathrm{~mm}$.

The occlusal surface of each tooth was etched and the adhesive system (Futurabond M+, Voco GmbH, Germany) was applied according to the manufacturer's instructions. For all teeth, resin composite was packed on the occlusal surface using a Teflon mold especially constructed for each thickness $(8 \times 8 \times 4$ and $8 \times 8 \times 6)$. Composite buildup of $\mathrm{C} 0$ group was done incrementally using nanohybrid resin composite. For preparation of $\mathrm{C} 1$ and $\mathrm{C} 2$ samples, Cention $\mathrm{N}$ was prepared by manual mixing of one measuring scoop of powder and one drop of liquid according to manufacturer's instructions. Where samples of $\mathrm{C} 1$ group were chemically cured and those

Table 1 Materials' description, composition, and manufacturers

\begin{tabular}{|c|c|c|c|c|}
\hline Materials & Description & Composition & Manufacture & Batch numbers \\
\hline Meta Etchant & Etchant gel & $\begin{array}{l}\text { Nondripping gel consistency } \\
34.9 \% \text { phosphoric acid } \\
\text { Blue color for visual control }\end{array}$ & $\begin{array}{l}\text { Meta Biomed Co., } \\
\text { Ltd.; Cheougja City, } \\
\text { Chungbuk, Korea }\end{array}$ & 1906071 \\
\hline Futurabond M+ & Universal adhesive & $\begin{array}{l}\text { Hydroxyethyl methacrylate (10-25\%), BIS- } \\
\text { GMA (10-25\%), ethanol (10-25\%), acidic } \\
\text { adhesive monomer (2.5-5\%), urethane } \\
\text { dimethacrylate (2.5-5\%), catalyst, and } \\
\text { camphorquinone }\end{array}$ & Voco GmbH & 1801228 \\
\hline Grandio & $\begin{array}{l}\text { Nanohybrid resin composite } \\
\text { shade A2 }\end{array}$ & $\begin{array}{l}\text { Resin: Bis-GMA, TEGDMA. Filler: Ba-Al-Si } \\
\text { glass/silica nanoparticles. Inorganic filler } \\
\text { loading is } 89 \% \text { by weight and } 71.4 \% \\
\text { by volume with a particle size range of } \\
20-40 \mathrm{~nm}\end{array}$ & Voco GmbH & 1702120 \\
\hline Cention N & $\begin{array}{l}\text { Resin composite with alkaline } \\
\text { fillers Cention N shade A2 }\end{array}$ & $\begin{array}{l}\text { Powder: calcium fluorosilicate glass, } \\
\text { barium glass, calcium-barium-aluminum } \\
\text { fluorosilicate glass, isofillers, ytterbium } \\
\text { trifluoride, initiators, and pigments. } \\
\text { Cention N contains } 78.4 \text { wt\% or } 57.6 \text { vol\% } \\
\text { of inorganic fillers } \\
\text { Liquid: dimethacrylates, initiators, } \\
\text { stabilizers, and additives }\end{array}$ & $\begin{array}{l}\text { Ivoclar Vivadent; } \\
\text { Schaan, } \\
\text { Liechtenstein }\end{array}$ & X40020 \\
\hline
\end{tabular}


of C2 group were light activated using light curing unit (Elipar S10; 3MESPE, St. Paul, Minnesota, United States).

Each sample was mounted in the gripping attachment and serially sectioned perpendicular to the bonded interface using 0.3-mm-thick diamond-coated disc mounted in microsaw (Isomet 4000, Buehler Ltd.) under copious coolant. The resultant beams were $0.9 \pm 0.1 \mathrm{~mm}$ in thickness and $6 \pm 1 \mathrm{~mm}$ in length for T1 group and $8 \pm 1 \mathrm{~mm}$ for T2 group. A digital caliper (Mitutoyo, Japan) was used to check the thickness and length of all beams. ${ }^{12}$

The prepared beams were used for assessment of $\mu$ TBS using universal testing machine. Each beam was aligned in the central groove of the Geraldeli's jig and glued in place by its ends using cyanoacrylate-based glue (Zapit, DVA Inc, United States). The jig was in turn mounted into the universal testing machine (Instron, Massachusetts, United States) with a load cell of $500 \mathrm{~N}$, at a cross-head speed of $0.5 \mathrm{~mm} / \mathrm{min}$, until failure of the specimen occurred. Bond strength was calculated in Mega Pascal (Bluehill Lite software, Instron). ${ }^{13}$

\section{Microleakage Assessment}

Fifteen human impacted mandibular third molars freshly extracted for orthodontic treatment from patients in the age range 20 to 30 years were collected and cleaned. Standardized mesio-occlusal cavities were performed ( $5 \mathrm{~mm}$ buccolingual width, $2 \mathrm{~mm}$ in depth, and $2 \mathrm{~mm}$ axial depth). Teeth were then randomly assigned to three experimental groups $(n=5)$ according to the resin composite material $(\mathrm{CO}, \mathrm{C} 1$, and $\mathrm{C} 2)$ as mentioned in $\mu$ TBS test. Tofflemire metal matrix holder was securely adjusted to encircle the prepared cavity of each tooth after fixing of each one in acrylic resin mold. ${ }^{14}$ All samples were etched and the adhesive system (Futurabond $\mathrm{M}+$, Voco GmbH, Germany) was applied according to manufacturer's instructions. Restoration of samples of C0 group was done incrementally using Grandio nanohybrid resin composite and polymerized according to manufacturer's instructions. For restoration of $\mathrm{C} 1$ and $\mathrm{C} 2$ samples, Cention $\mathrm{N}$ was applied as bulk according to manufacturer's instructions. As described for microtensile testing samples of $\mathrm{C} 1$ group were chemically cured and those of C2 group were light activated using light curing unit.

All restored samples were thermocycled for 1,000 cycles in a water bath at $5^{\circ} \mathrm{C}$ followed by $55^{\circ} \mathrm{C} .{ }^{15}$ After thermocycling, each tooth's apex was sealed with wax and its entire surface was covered with two layers of nail varnish. ${ }^{16}$ All teeth were immersed in $0.1 \%$ methylene blue stain for 24 hours at room temperature, then removed and rinsed thoroughly under running water and sectioned mesiodistally. Dye penetration along both occlusal $(0)$ and gingival margins $(G)$ was evaluated at $\times 50$ magnification with a stereomicroscope (Nikon MA100 stereomicroscope, Japan). Each image of the restoration was captured and transferred to a computer equipped with the image analysis software program (Omnimet Buehler, United States), where the leakage was assessed in microns.

\section{Evaluation of Antibacterial Effect}

Resin composite discs were prepared for the tested groups $(\mathrm{C} 0, \mathrm{C} 1$, and $\mathrm{C} 2)(n=5)$ using a specially constructed flat Teflon mold with a diameter of 6 and $2 \mathrm{~mm}$ thickness. ${ }^{17}$ Streptococcus mutans serotype $\mathrm{c}$ that was isolated carious dentin (ATCC25175 type strain) was incubated for 24 hours at $37^{\circ} \mathrm{C}$ in incubator. ${ }^{18}$ Preparation of resin composite discs was achieved through packing of each material within the mold, covering its top and bottom surfaces with celluloid papers, and pressing it in between two glass slaps to ensure a standard flat smooth disc surface. Resin composite discs for both C0 and C2 groups were light cured as mentioned before, meanwhile those related to $\mathrm{C} 1$ group were self-cured. Finally, Chlorhexidine $\mathrm{HCl}$ applied on filter paper of the same dimensions of the discs in a concentration of $0.075 \mathrm{ppm}$ was used as a control positive group $(C+v e)$.

Agar diffusion test using a base layer containing $15 \mathrm{~mL}$ nutrient agar reinforced with $2 \mathrm{~g}$ of sucrose and $2 \mathrm{~g}$ of glucose " 0.4 sugar concentration \% " per $100 \mathrm{~mL}$ was used to culture the bacteria. ${ }^{19}$ Agar was evenly spread in a sterile petri dish. In each petri dish, four wells equivalent to the diameter of discs were made using the blunt end of a micropipette tip. Each dish involved disc representing to the tested groups. A total of $100 \mu \mathrm{L}$ of bacterial suspension was poured over the agar surface with a micropipette and spread evenly. The culture plates were placed in incubator at $37^{\circ} \mathrm{C}$ and their antibacterial activity was evaluated after 48 hours. After incubation, the plates were removed from the incubator and the diameter of bacterial inhibition zones was measured in millimeters using a digital caliper. Measurements were taken at the greatest distance between two points on the outer limit of the inhibition zone formed around the wells. This measurement was repeated three times and the means were calculated for each well. ${ }^{17}$

Broth dilution method was used as a confirmatory method to the antibacterial effect of both $\mathrm{C} 1$ and $\mathrm{C} 2$ groups. Streptococcus mutans strain was cultured on MuellerHinton agar and incubated for 24 hours. For the preparation of the broth, five different bacterial concentrations were serially diluted by normal saline $\left(10^{6}, 10^{5}, 10^{4}, 10^{3}\right.$, and $10^{2} \mathrm{CFU} / \mathrm{mL}$ ), where tubes that contain higher bacterial concentrations appear more turbid than tubes with lower bacterial concentration. Chlorhexidine $\mathrm{HCl}$ in a concentration of $0.075 \mathrm{ppm}$ was used as a $\mathrm{C}+\mathrm{ve}$, meanwhile tubes of broth with different concentrations without adding of any tested materials were used as a control negative group ( $\mathrm{C}-\mathrm{ve})$. The broth was used for filling of 20 sterile tubes which were distributed into four groups (C1, C2, C -ve, and C +ve) five tubes each, where each group involving the five different concentrations. For each of $\mathrm{C} 1$ and $\mathrm{C} 2$ groups, five resin composite discs were prepared as previously mentioned in the agar diffusion method. Later on, one resin composite disc from each group was immersed in one tube from each broth concentrations. After incubation of all tubes at $37^{\circ} \mathrm{C}$ for 48 hours, a change in broth turbidity was observed and is considered as an indicator for the antibacterial effect. ${ }^{20}$

\section{Statistical Analyses}

The mean and standard deviation values were calculated for each group in each test. Data were explored for 
normality using Kolmogorov-Smirnov's and ShapiroWilk's tests, data showed parametric (normal) distribution. Two-way analysis of variance (ANOVA) test was used to test the interactions between different variables. Oneway ANOVA followed by post hoc Tukey's test was used to compare between more than two groups in nonrelated samples. Independent sample $t$-test was used to compare between two groups in nonrelated samples. The significance level was set at $p \leq 0.05$. Statistical analysis was performed with IBM SPSS statistics version 20 for Windows.

\section{Results}

\section{Microtensile Bond Strength Results Two-Way ANOVA}

Data in - Table 2 show the results of two-way ANOVA analysis for the interaction of different variables. The results showed that material had no statistically significant effect. Also, thickness had no statistically significant effect. The interaction between the two variables also had no statistically significant effect.

Effect of Different Resin Composite Material on $\mu$ TBS at $4 \mathrm{~mm}$ (T1) Thickness

Resin composite with alkaline fillers (Cention $\mathrm{N}$ ) (dual-cured) (C2) group showed the highest $\mu$ TBS value to dentine followed by resin composite with alkaline fillers (Cention N) (self-cured) (C1) group and nanohybrid resin composite (Grandio) ( $\mathrm{C} 0$ ), respectively, with no statistically significant difference between them.
Effect of Different Resin Composite Material on $\mu$ TBS at $6 \mathrm{~mm}$ (T2) Thickness

Resin composite with alkaline fillers (Cention N) (self-cured) (C1) group showed the highest $\mu$ TBS value to dentine followed by nanohybrid resin composite (Grandio) (CO) group and resin composite with alkaline fillers (Cention $\mathrm{N}$ ) (dual-cured) (C2) group, respectively, with no statistically significant difference between them.

Effect of Resin Composite Thickness on $\mu$ TBS at

Nanohybrid resin composite (Grandio) (CO): Six-mmthickness (T2) subgroup showed $\mu$ TBS mean value slightly higher than 4-mm-thickness (T1) subgroup with no statistically significant difference between them.

Self-cured resin composite with alkaline fillers (Cention $N$ ) (C1): Four-mm-thickness (T1) subgroup showed $\mu$ TBS mean value higher than 6-mm-thickness (T2) subgroup with no statistically significant difference between them.

Dual-cured resin composite with alkaline fillers (Cention $N$ ) (CO): Four-mm-thickness (T1) subgroup showed $\mu$ TBS mean value higher than 6 -mm-thickness (T2) subgroup with no statistically significant difference between them ( - Table $\mathbf{3}$ ).

\section{Microleakage \\ Two-Way ANOVA}

Data in - Table 4 show the results of two-way ANOVA analysis for the interaction of different variables. The results showed that material type had a statistically significant effect. Marginal position also had a statistically significant effect.

Table 2 Results of two-way ANOVA for the effect of different variables on microtensile bond strength

\begin{tabular}{|l|l|l|l|l|l|}
\hline Source & Type III sum of squares & df & Mean square & F & Significance \\
\hline Corrected model & $507.390^{\text {a }}$ & 5 & 101.478 & 1.077 & 0.398 \\
\hline Intercept & $23,185.200$ & 1 & $23,185.200$ & 245.963 & 0.000 \\
\hline Mode of curing & 129.592 & 2 & 64.796 & 0.687 & 0.513 \\
\hline Thickness & 42.293 & 1 & 42.293 & 0.449 & 0.509 \\
\hline Mode of curing thickness & 335.505 & 2 & 167.752 & 1.780 & 0.190 \\
\hline Error & $2,262.310$ & 24 & 94.263 & & \\
\hline Total & $25,954.900$ & 30 & & & \\
\hline Corrected total & $2,769.700$ & 29 & & & \\
\hline
\end{tabular}

Abbreviations: ${ }^{\mathrm{A}} \mathrm{ANOVA}$, analysis of variance; $\mathrm{df}$, degrees of freedom $=(n-1)$.

bSignificant at $p \leq 0.05$.

Table 3 Mean and SD values of microtensile bond strength of different groups

\begin{tabular}{|c|c|c|c|c|c|c|c|}
\hline \multirow[t]{3}{*}{ Variables } & \multicolumn{7}{|c|}{ Microtensile bond strength } \\
\hline & \multicolumn{2}{|c|}{ Light-cured composite (CO) } & \multicolumn{2}{|c|}{$\begin{array}{c}\text { Self-cured } \\
\text { composite (C1) }\end{array}$} & \multicolumn{2}{|c|}{$\begin{array}{c}\text { Dual-cured } \\
\text { composite (C2) }\end{array}$} & \multirow[t]{2}{*}{$p$-Value } \\
\hline & Mean & SD & Mean & SD & Mean & SD & \\
\hline $4 \mathrm{~mm}(\mathrm{~T} 1)$ & $24.76^{\mathrm{aA}}$ & 11.47 & $31.54^{\mathrm{aA}}$ & 9.07 & $34.66^{\mathrm{aA}}$ & 11.56 & 0.376 \\
\hline $6 \mathrm{~mm}(\mathrm{~T} 2)$ & $25.64^{\mathrm{aA}}$ & 8.85 & $27.54^{\mathrm{aA}}$ & 10.14 & $22.66^{\mathrm{aA}}$ & 6.07 & 0.252 \\
\hline$p$-Value & \multicolumn{2}{|c|}{0.895} & \multicolumn{2}{|c|}{0.530} & \multicolumn{2}{|c|}{0.074} & \\
\hline
\end{tabular}

Abbreviation: SD, standard deviation.

Note: Means with the same letter are not significantly different, $p<0.05$. 
Table 4 Results of two-way ANOVA for the effect of different variables on microleakage

\begin{tabular}{|l|l|l|l|l|l|}
\hline Source & Type III sum of squares & df & Mean square & F & Significance \\
\hline Corrected model & $11,754,039.100^{\text {a }}$ & 5 & $2,350,807.820$ & 98.637 & 0.000 \\
\hline Intercept & $46,732,608.300$ & 1 & $46,732,608.300$ & $1,960.838$ & 0.000 \\
\hline Material type & $5,546,067.800$ & 2 & $2,773,033.900$ & 116.353 & 0.000 \\
\hline Marginal position & $6,193,472.033$ & 1 & $6,193,472.033$ & 259.870 & 0.000 \\
\hline $\begin{array}{l}\text { Material type } \\
\text { position }\end{array}$ & $14,499.267$ & 2 & $7,249.633$ & 0.304 & 0.741 \\
\hline Error & $571,991.600$ & 24 & $23,832.983$ & & \\
\hline Total & $59,058,639.000$ & 30 & & & \\
\hline Corrected total & $12,326,030.700$ & 29 & & & \\
\hline
\end{tabular}

Abbreviations: aNOVA, analysis of variance; df, degrees of freedom $=(n-1)$.

bignificant at $p \leq 0.05$

Effect of Resin Composite Material on the Microleakage Results of

Nanohybrid resin composite (Grandio) (CO): Occlusal margin showed the lowest microleakage mean value with a statistically significant difference with gingival mean value (-Fig. 1).

Resin composite with alkaline fillers (Cention $N$ ) (self-cured) (C1): Occlusal margin showed the lowest microleakage mean value with a statistically significant difference with gingival mean value (-Fig. 2 ).

Resin composite with alkaline fillers (Cention $N$ ) (dual-cured) (C2): Occlusal margin showed the lowest microleakage mean value with a statistically significant difference with gingival mean value (-Fig. 3).

Effect of resin composite material on the microleakage results of

Gingival margin: Nanohybrid resin composite (Grandio) (C0) group showed the highest microleakage mean value, followed by resin composite with alkaline fillers (Cention N)(dual-cured) (C2) group, meanwhile the lowest microleakage value was found in resin composite with alkaline fillers (Cention $\mathrm{N}$ ) (self-cured) (C1) group. There was a statistically significant difference between $\mathrm{CO}, \mathrm{C} 1$, and $\mathrm{C} 2$ groups (-Table 5).

Occlusal margin: Nanohybrid resin composite (Grandio) (CO) group showed the highest microleakage mean value, followed by resin composite with alkaline fillers (Cention $\mathrm{N}$ ) (dual-cured) (C2) group, finally the lowest microleakage value was found in resin composite with alkaline fillers (Cention N) (self-cured) (C1) group. There was a statistically significant difference between $\mathrm{C} 0, \mathrm{C} 1$, and $\mathrm{C} 2$ groups.

\section{Antibacterial Effect Results}

\section{Agar Disc Diffusion Results}

Dual-cured resin composite with alkaline fillers (Cention $\mathrm{N}$ ) (C2) group showed comparable inhibition zone diameter mean value $(11 \pm 2.74 \mathrm{~mm})$ followed by chlorhexidine $(\mathrm{C}+\mathrm{ve})$ group $(10.40 \pm 1.34 \mathrm{~mm})$ and self-cured resin composite with alkaline fillers (Cention $N$ ) (C2) group $(10.60 \pm 1.67 \mathrm{~mm})$, respectively. Meanwhile, nanohybrid resin composite (Grandio) showed no inhibition zone. There was no statistically significant difference between $C$

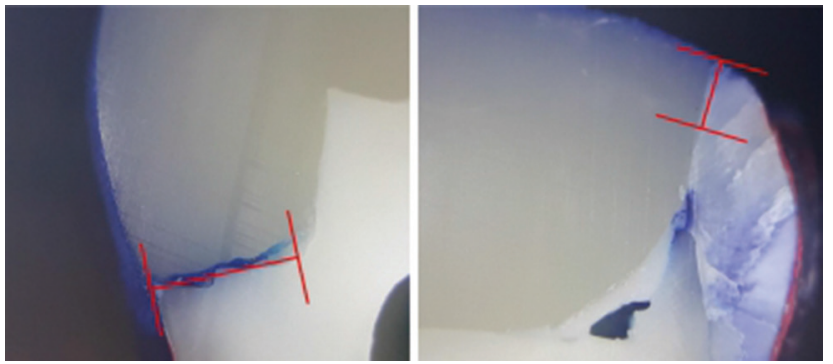

Fig. 1 Depth of dye penetration at gingival and occlusal margins in Grandio composite.
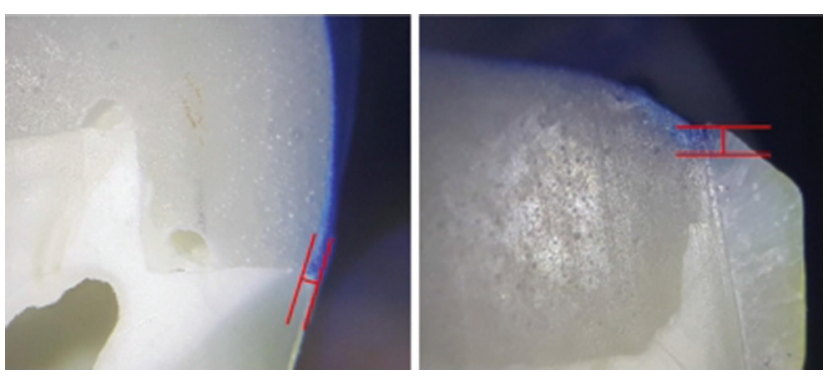

Fig. 2 Depth of dye penetration at gingival and occlusal margins in self-cured Cention N.
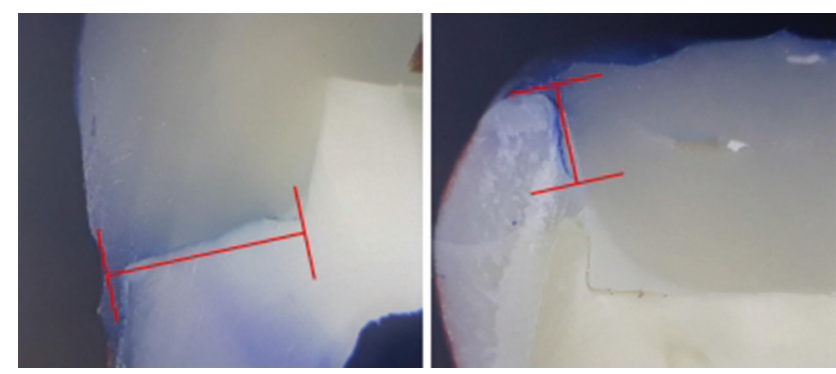

Fig. 3 Depth of dye penetration at gingival and occlusal margins in dual-cured Cention N.

+ve, C1, and C2 groups, but there was a statistically significant difference between $\mathrm{C} 0$ and each of $\mathrm{C}+\mathrm{ve}, \mathrm{C} 1$, and $\mathrm{C} 2$ group (-Fig. 4). 
Table 5 Mean and SD of microleakage values for different tested groups

\begin{tabular}{|c|c|c|c|c|c|c|c|}
\hline \multirow[t]{3}{*}{ Variables } & \multicolumn{7}{|c|}{ Microleakage } \\
\hline & \multicolumn{2}{|c|}{$\mathrm{CO}$} & \multicolumn{2}{|c|}{$\mathrm{C} 1$} & \multicolumn{2}{|c|}{$\mathrm{C} 2$} & \multirow[t]{2}{*}{ p-Value } \\
\hline & Mean & SD & Mean & SD & Mean & SD & \\
\hline Gingival & $2,233.40^{\mathrm{aA}}$ & 308.63 & $1,221.40^{\mathrm{ac}}$ & 83.94 & $1,652.60^{\mathrm{aB}}$ & 95.79 & $<0.001$ \\
\hline Occlusal & $1,382.40^{\mathrm{bA}}$ & 118.45 & $303.80^{\mathrm{bc}}$ & 40.79 & $695.00^{\mathrm{bB}}$ & 125.80 & $<0.001$ \\
\hline$p$-Value & \multicolumn{2}{|c|}{$<0.001$} & \multicolumn{2}{|c|}{$<0.001$} & \multicolumn{2}{|c|}{$<0.001$} & \\
\hline
\end{tabular}

Abbreviation: SD, standard deviation.

Note: Means with the same letter within each row are not significantly different, $p<0.05$.

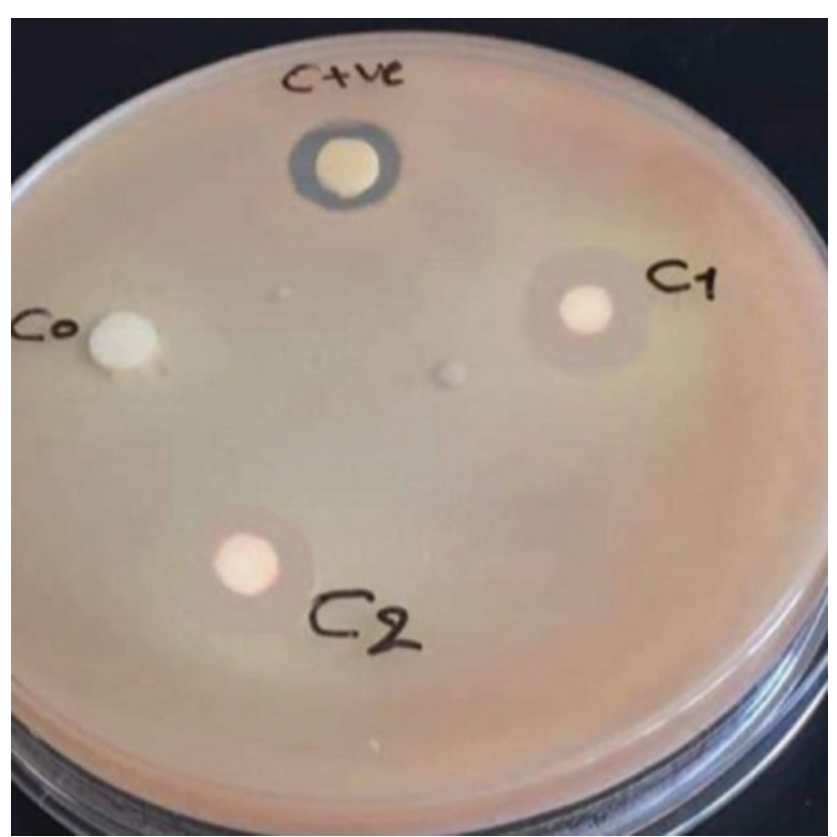

Fig. 4 Image of bacterial growth inhibition zones on agar plate inoculated with Streptococcus mutan.

\section{Broth Dilution Results}

Massive reduction in bacterial turbidity was noticed in chlorhexidine $(C+v e)$ group tubes at all bacterial concentrations. While self- and dual-cured composites resin with alkaline fillers (Cention $\mathrm{N}$ ) showed no change in broth turbidity at $1 \times 106$ and $1 \times 105 \mathrm{CFU} / \mathrm{mL}$ concentrations of bacterial strains. However, they showed a gradual decrease in bacterial turbidity at lower bacterial concentrations $1 \times 104,1 \times 103$, and $1 \times 102 \mathrm{CFU} / \mathrm{mL}$. Consequently, their maximum broth clarity was noticed for the lowest bacterial concentration $1 \times 10^{2}$ $\mathrm{CFU} / \mathrm{mL}$ bacterial strains ( - Fig. 5 ).

\section{Discussion}

\section{Microtensile Bond Strength}

In the present study, bond strength assessment was performed using $\mu \mathrm{TBS}$ as it corresponds more reliably with clinical outcomes than microshear bond strength test. ${ }^{21}$ For better control of regional differences, only beams from the central part of each sample were chosen. ${ }^{22}$ Also, the peripheral beams may not have the same thickness of the
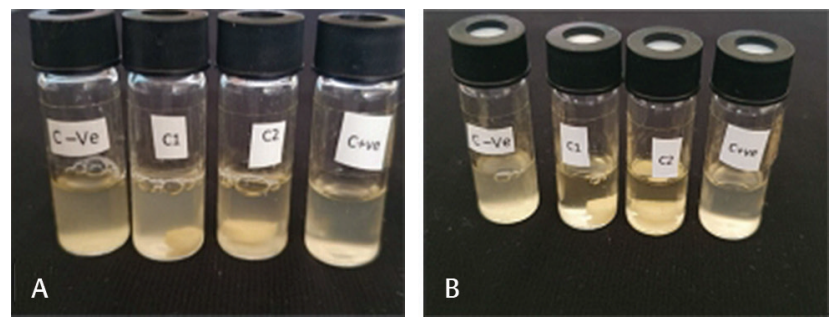

Fig. 5 Broth turbidity at highest (A) and lowest (B) bacterial concentrations.

dentin and a better distribution of pressure at the true interface. ${ }^{23}$

For the current test, the bonded area of samples is small stick shaped, around $(0.9 \mathrm{~mm} \times 0.9 \mathrm{~mm}) \pm 0.1$ which is critical for producing better stress distribution at the adhesive joint, minimizing cohesive failures in tooth substrate or composite, ${ }^{22}$ and length of $8 \pm 1$ was used in the current study due to the increased bulk thickness of composite samples. In this analysis, bond strength to dentin was measured at the level of deep dentin on a flat dentin layer, ${ }^{24}$ as this type of resin composite restoration is fabricated specially for large deep cavities.

Concerning the effect of different resin composite materials on mean $\mu$ TBS regardless of bulk thickness, the results of $\mu$ TBS showed that self-cured Cention N (C1) has slightly higher $\mu$ TBS mean value without significant difference with nanohybrid resin composite. This might be because that Cention $\mathrm{N}$ is a self-curing resin composite material, so its curing depth is theoretically unlimited, besides the presence of the stress reliever isofiller. ${ }^{10}$ This result come in agreement with Mandava et al (2017), who reported that there was no significant difference between nanohybrid composite and another commercially available bulk fill composite (Filtek bulk fill). ${ }^{25}$ On the contrary, the results come in disagreement with Taneja et al (2016), who found that bulk fill resin composite showed significantly higher $\mu \mathrm{TBS}$ in comparison to incremental nanohybrid resin composite. This difference might be due to that they used sonic bulk fill which have special chemistry, viscosity, and modifiers that react to sonic energy. As sonic waves are applied through the handpiece, the modifiers cause the viscosity of the composite to drop up to $87 \%$. This increases the flowability, quick placement, and precise adaptation of the composite to the cavity walls. Composite returns to a more sticky and nonslumping state as the sonic energy is stopped. ${ }^{26}$ 
Regarding the effect of bulk thickness for all tested materials, 4-mm bulk thickness is slightly higher in $\mu$ TBS mean value than 6 -mm bulk thickness with a statistically nonsignificant difference between them. This slight increase in $\mu$ TBS might be related to high polymerization contraction stresses created during curing of a large volume of resin composite in 6-mm-thickness samples, but the lack of significant difference between them might be due to that all the specimens had the same low C-factor that is referred to bonding of resin composite materials to flat dentine surface. This result come in agreement with Sagsoz et al (2016), who reported that there is no significant difference in $\mu$ TBS recorded for resin composite used in different thicknesses. ${ }^{27}$ But the result come in disagreement with Silame et al (2017), who reported that the 2-mm increment restorations in box-shaped cavities yielded higher $\mu \mathrm{TBS}$ than 4-mm increment restoration for both conventional and bulk fill composites. ${ }^{28}$ This result might be due to that they used molars with class I cavities which is different from the flat occlusal surface used in the current study. Also, the result comes in disagreement with Taneja et al (2016), who reported that both nanohybrid composite and sonic bulk fill resin composite showed higher $\mu$ TBS at $4 \mathrm{~mm}$ than at $6 \mathrm{~mm}$ with significant difference between them. This might be due to the insufficient light curing at $6 \mathrm{~mm}$ depth that resulted from the increased distance from the light source. This might have resulted in insufficient polymerization of the base of sonic bulk fill resin composite at $6 \mathrm{~mm}$ depth. ${ }^{26}$

\section{Microleakage}

Dye penetration is an in vitro method developed to investigate marginal leakage along the tooth restoration interface. ${ }^{29}$ Methylene blue dye was used in this study as its molecular size is $\sim 1 \mathrm{~nm}$ which is smaller than the diameter of the dentinal tubule, so it can penetrate through gaps between restoration and tooth. ${ }^{30}$ The total depth of dye penetration along the tooth restoration interface was measured by an image analysis software program, which is a more accurate method than the visual (scores) method. ${ }^{31}$

Evaluating the effect of different resin composite materials on microleakage regardless of marginal position showed that self-cured Cention $\mathrm{N}$ has a statistically significantly lower microleakage value than the dual-cured one. This result might be attributed to using self-cured resin composite material with a slow polymerization rate which may be an effective way to reduce the risk of marginal microleakage at the tooth restoration interface. ${ }^{32}$ So that both self- and dual-cured Cention $\mathrm{N}$ showed statistically significantly lower microleakage values than nanohybrid resin composite. Also, these results could be explained based on that Cention $\mathrm{N}$ contains a shrinkage stress reliever (isofiller) with a low modulus of elasticity that acts like a microscopic spring, attenuating the forces generated during polymerization shrinkage. ${ }^{10}$ The difference in results between $\mu$ TBS and microleakage values might be attributed to higher C-factor values related to microleakage samples which were prepared as class II cavities, meanwhile samples prepared for $\mu$ TBS were bonded to flat dentin surfaces that can affect the developing stresses when cavities are restored with resin composite. ${ }^{33}$

Evaluation of the effect of marginal position regardless of the material revealed that there was a significant difference between both gingival and occlusal microleakage values in all tested materials, where microleakage at the gingival margin was significantly higher. This result could be due to that the gingival margin is one of the weakest links of class II resin composite restoration due to inadequate enamel thickness. Also, this could be attributed to enamel microfractures that occurred in many restorations along gingival margins immediately after polymerization of resin composite bonded to etched enamel surfaces. ${ }^{34}$

\section{Antibacterial Effect}

The agar diffusion method was used in the current study for evaluating the antibacterial efficiency of Cention $\mathrm{N}$ resin composite material. Multiple articles confirmed that this method is characterized by being an effective and easy way for antibacterial effect detection. ${ }^{35}$ Chlorhexidine was used as a control positive material as it is considered the gold standard chemical plaque control agent. ${ }^{36}$

Agar disc diffusion test showed that there was no antibacterial effect for nanohybrid resin composite. This result might be due to the absence of any antibacterial substances in conventional nanohybrid resin composite.

Although there was a nonsignificant difference in the antibacterial effect of chlorhexidine and both of self-cured and dual-cured Cention $\mathrm{N}$ in terms of inhibition zone diameter, the inhibition zone around Cention $\mathrm{N}$ was less clear than that noticed around chlorhexidine. So, another confirmatory test was done using broth dilution which is another accurate confirmatory way. This method depends on the fact that broth turbidity made by bacteria is decreased by the antibacterial agent, so multiple bacterial dilutions could be used for detecting the antibacterial effect depending on the level of the turbidity clearance. The results of broth dilution method at high bacterial concentrations for both self-cured and dual-cured Cention $\mathrm{N}$ showed no decrease in broth turbidity. But at low bacterial concentrations, they showed a marked decrease in the broth turbidity with an almost clear appearance which was comparable to that of the $\mathrm{C}+$ ve group. ${ }^{20}$ This weak antibacterial effect could be attributed to that there is a positive correlation between the amount of fluoride released and the amount of antibacterial effect.

Although the results indicated that Cention $\mathrm{N}$ is characterized by a weak antibacterial effect in comparison to chlorhexidine, this effect could be of value in minimizing the caries recurrence at tooth restoration interfaces.

\section{Conclusion}

Under the limitations of the current study, the following could be concluded:

1. $\mu$ TBS of bulk fill resin composite with alkaline fillers "either self- or dual-cured" material is comparable to that of incremental nanohybrid resin composite. 
2. Microleakage of resin composite with alkaline fillers is significantly better than the conventional nanohybrid resin composite restorations in short-term aging. Also, occlusal microleakage is better than cervical one.

3. Resin composite with alkaline fillers is characterized by weak antibacterial effect in comparison to chlorhexidine.

\section{Conflict of Interest}

None declared.

\section{References}

1 Tarle Z, Meniga A, Knezević A, Sutalo J, Ristić M, Pichler G. Composite conversion and temperature rise using a conventional, plasma arc, and an experimental blue LED curing unit. J Oral Rehabil 2002;29(7):662-667

2 Knezević A, Tarle Z, Meniga A, Sutalo J, Pichler G, Ristić M. Degree of conversion and temperature rise during polymerization of composite resin samples with blue diodes. J Oral Rehabil 2001;28(6):586-591

3 Andrzejewska E. Photopolymerization kinetics of multifunctional monomers. Prog Polym Sci 2001;26(4):605-665

4 Price RB, Murphy DG, Dérand T. Light energy transmission through cured resin composite and human dentin. Quintessence Int 2000;31(9):659-667

5 Poskus LT, Placido E, Cardoso PE. Influence of placement techniques on Vickers and Knoop hardness of class II composite resin restorations. Dent Mater 2004;20(8):726-732

6 Sakaguchi RL, Douglas WH, Peters MC. Curing light performance and polymerization of composite restorative materials. J Dent 1992;20(3):183-188

7 Pilo R, Oelgiesser D, Cardash HS. A survey of output intensity and potential for depth of cure among light-curing units in clinical use. J Dent 1999;27(3):235-241

8 Flury S, Hayoz S, Peutzfeldt A, Hüsler J, Lussi A. Depth of cure of resin composites: is the ISO 4049 method suitable for bulk fill materials? Dent Mater 2012;28(5):521-528

9 Abouelleil H, Pradelle N, Villat C, Attik N, Colon P, Grosgogeat B. Comparison of mechanical properties of a new fiber reinforced composite and bulk filling composites. Restor Dent Endod 2015;40(4):262-270

10 Todd JC. Scientific Documentation: Cention ${ }^{\circledR}$ N. Schaan, Liechtenstein: Ivoclar-Vivadent Press; 2016:1-58

11 Van Ende A, De Munck J, Lise DP, Van Meerbeek B. Bulkfill composites: a review of the current literature. J Adhes Dent 2017;19(2):95-109

12 Lima JFM, Wajngarten D, Islam F, Clifford J, Botta AC. Effect of adhesive mode and chlorhexidine on microtensile strength of universal bonding agent to sound and caries-affected dentins. Eur J Dent 2018;12(4):553-558

13 Follak AC, Miotti LL, Lenzi TL. Rocha RO, Maxnuck Soares FZ. The impact of artificially caries-affected dentin on bond strength of multi-mode adhesives. J Conserv Dent 2018;21(2):136-141

14 El-Shamy H, Sonbul H, Alturkestani N, et al. Proximal contact tightness of class II bulk-fill composite resin restorations: an in vitro study. Dent Mater J 2019;38(1):96-100

15 Swapna MU, Koshy S, Kumar A, Nanjappa N, Benjamin S, Nainan MT. Comparing marginal microleakage of three bulk fill composites in class II cavities using confocal microscope: an in vitro study. J Conserv Dent 2015;18(5):409-413

16 Mutluay AT, Mutluay M. Effects of different disinfection methods on microleakage of giomer restorations. Eur J Dent 2019;13(4):569-573

17 Hotwani K, Thosar N, Baliga S, Bundale S, Sharma K. Antibacterial effects of hybrid tooth colored restorative materials against Streptococcus mutans: an in vitro analysis. J Conserv Dent 2013;16(4):319-322

18 Clarke JK. On the bacterial factor in the etiology of dental caries. Br J Exp Pathol 1924;5:141-147

19 Atlas, Ronald M, Julian E Davies, and Arnold L Demain. Manual of Industrial Microbiology and Biotechnology. 2nd ed. Washington (D.C.): ASM press; 1999

20 Cosgun A, Bolgul B, Duran N. In vitro investigation of antimicrobial effects, nanohardness, and cytotoxicity of different glass ionomer restorative materials in dentistry. Niger J Clin Pract 2019;22(3):422-431

21 Heintze SD. Clinical relevance of tests on bond strength, microleakage and marginal adaptation. Dent Mater 2013;29(1):59-84

22 Sano H, Shono T, Sonoda H, et al. Relationship between surface area for adhesion and tensile bond strengthevaluation of a micro-tensile bond test. Dent Mater $1994 ; 10(4): 236-240$

23 Abdalla AI. Effect of long-term water aging on microtensile bond strength of self-etch adhesives to dentin. Am J Dent 2010;23(1):29-33

24 Sharafeddin F, Salehi R, Feizi N. Effect of dimethyl sulfoxide on bond strength of a self-etch primer and an etch and rinse adhesive to surface and deep dentin. J Dent (Shiraz) 2016;17(3, Suppl):242-249

25 Mandava J, Vegesna DP, Ravi R, Boddeda MR, Uppalapati LV, Ghazanfaruddin MD. Microtensile bond strength of bulk-fill restorative composites to dentin. J Clin Exp Dent 2017;9(8):e1023-e1028

26 Taneja S, Kumar P, Kumar A. Comparative evaluation of the microtensile bond strength of bulk fill and low shrinkage composite for different depths of Class II cavities with the cervical margin in cementum: an in vitro study. J Conserv Dent 2016;19(6):532-535

27 Sagsoz O, Ilday NO, Karatas O, et al. The bond strength of highly filled flowable composites placed in two different configuration factors. J Conserv Dent 2016;19(1):21-25

28 Silame FDJ, Geraldeli GP, Sinhoreti MAC, Pires-de-Souza FCP, Roulet JF, Geraldeli S. Dentin $\mu$ TBS and hardness of bulk-fill and conventional composites placed in a box-shaped cavity preparation. J Adhes Dent 2017;19(5):395-400

29 Kusgoz A, Ülker M, Yesilyurt C, Yoldas OH, Ozil M, Tanriver M. Silorane-based composite: depth of cure, surface hardness, degree of conversion, and cervical microleakage in Class II cavities. J Esthet Restor Dent 2011;23(5):324-335

30 Abrol A, Aggarwal N, Gupta P, Kunjam M, Abrol N. Comparative evaluation of microleakage around class ii cavities restored with Zirconomer, Tetric N Ceram, Cention-N and glass ionomer cement- an in vitro study. Int J Curr Res 2019;1(02):1641-1644

31 Alvarenga FAS, Pinelli C, Loffredo LCM. Reliability of marginal microleakage assessment by visual and digital methods. Eur J Dent 2015;9(1):1-5

32 Braga RR, Ferracane JL, Condon JR. Polymerization contraction stress in dual-cure cements and its effect on interfacial integrity of bonded inlays. J Dent 2002;30(7-8):333-340

33 El-Sahn NA, El-Kassas DW, El-Damanhoury HM, Fahmy OM, Gomaa H, Platt JA. Effect of C-factor on microtensile bond strengths of low-shrinkage composites. Oper Dent 2011;36(3):281-292

34 Han L, Okamoto A, Iwaku M. The effect of various clinical factors on marginal enamel micro-cracks produced around composite restorations. Dent Mater 1990;11:26-37

35 Jorgensen JH, Ferraro MJ. Antimicrobial susceptibility testing: a review of general principles and contemporary practices. Clin Infect Dis 2009;49(11):1749-1755

36 Balagopal S, Arjunkumar R. Chlorhexidine: the gold standard antiplaque agent. J Pharm Sci Res 2013;5(12):270-274 